\title{
AGAVE SISALANA AS A BIOMASS SOURCE FOR ETHANOL PRODUCTION
}

\author{
Ana Laíse do Nascimento dos Santos ${ }^{1}$, Érika Durão Vieira ${ }^{a, b}$, Aline Mota ${ }^{a}$,Itana \\ Rodrigues Ferreira ${ }^{a}$, Stephanie de Melo Santana ${ }^{a}$, Danilo Medeiros da Cruz ${ }^{a}$, \\ a , CENTRO UNIVERSITÁRIO SENAI CIMATEC, BRASIL, \\ ${ }^{b}$ Química e Petroquímica, SENAI CIMATEC
}

\begin{abstract}
Sisal, as it is popularly known in Brazil, is grown mainly in the northeastern region of the country due to its adaptability to semiarid climates. In this work, a review is presented for the implementation of a biorefinery to produce bio-ethanol using Agave sisalana as a biomass source, ranging from its socioeconomic aspects to the potential for current application in the Brazilian and worldwide market. A biorefinery concept based on this crop is proposed in light of the International Energy Agency (IEA) policies. The biorefinery proposal comprises 4 platforms and 6 products based on one feedstock, the Agave sisalana leave. A flowchart was designed and the biorefinery complexity index $(\mathrm{BCl})$ was calculated based on IEA TASK 42 . The focus was the juice platform which produces hecogenin derivatives, a high added value product compared to the others.
\end{abstract}

Keywords: Biorefinery; Agave Sisalana; Sisal; Biomass; Bio-Ethanol

\section{AGAVE SISALANA COMO FONTE DE BIOMASSA PARA A PRODUÇÃO DE ETANOL}

Resumo O Sisal, como a Agave sisalana é popularmente conhecida no Brasil, é cultivado principalmente no país na região nordeste do devido à sua adaptabilidade à climas semiáridos. Neste trabalho é apresentada uma revisão para implementação de uma a biorrefinaria de produção de etanol utilizando a agave sisalana como fonte de biomassa compreendendo desde os seus aspectos socioeconômicos até o potencial de aplicação atual no mercado brasileiro e mundial. Um conceito de biorrefinaria baseado neste vegetal é proposto à luz das políticas da Agência Internacional de Energia (IEA). A proposta de biorrefinaria é composta por 4 plataformas e 6 produtos a partir de uma matéria-prima, a folha de Agave sisalana. Um fluxograma foi desenhado e o índice de complexidade da biorrefinaria $(\mathrm{BCl})$ foi calculado com base na TASK 42 da IEA. O foco foi a plataforma de suco que produz derivados de hecogenina, um produto de alto valor agregado em comparação aos demais.

Palavras-chave: Biorrefinaria; Agave Sisalana; Sisal; Biomassa; Bio-Etanol. 


\section{INTRODUCTION}

Agave has shown in recent years as a promising source of bioenergy for several factors, such as low water demand, high in semiarid areas and adaptability to high temperatures, due to its strategies and metabolism that compare with other cellulosic sources of energy. a much greater $\mathrm{CO} 2$ capture potential for expelled $\mathrm{H} 2 \mathrm{O}$, reducing its energetic demand.[1]

The genus Agave comprises about 208 species and is the largest family of Agavaceae, which has the largest part of its native population in Mexico. Standing out among these Tequilana agave, Salmian agave, Fourcroydes agave and Sisalana agave used mainly for fiber and tequila production.[1]

Agave's average maturation time is 10 years, with the harvesting process beginning at eight years of cultivation under traditional planting systems. However, to meet the demand of the tequila industry, technologies were used to increase growth, while reducing harvest time. This information is important, for example, to evaluate the application of this plant, as a biofuel, whose production rate indicators per hectare are adaptable to different climatic conditions, biomass characteristics, etc.[1]

Sisal, as it is popularly known in Brazil, is cultivated mainly in the northeastern region of Brazil due to its adaptability to semi-arid climates, and also in a very artisanal way, where there is a high waste of raw materials such as bagasse and juice that have potential for transformation products of high commercial value.

For an comparison effect, the production of ethanol from Brazilian sugar cane, it is 30 to $50 \%$, lower than the cost of North American ethanol produced from corn and $75 \%$ of the cost of European ethanol from beet.Considering the advantages of agave when compared to sugar cane itself, the amount of cellulose, hemicellulose and lignin, which are considered residues from biomass sources, it is possible to note that agave has an advantage over sugar cane. What happens is that hemicellulose and lignin provide crystalline protection for cellulose and end up hindering the degradation of polymers for the production of fermentable sugars. Therefore, the less lignin and hemicellulose, the more easily the degradation of these polymers occurs. This parallel can be illustrated with the table (1) which shows the cellulose, hemicellulose and lignin yields for the the agave sisalana compared with sugar cane

Table 1. Cellulose, Hemicellulose and lignin yield comparison between sugar cane and agave sisalana

\begin{tabular}{|c|c|c|c|}
\hline & $\begin{array}{c}\text { Cellulose } \\
(\%)\end{array}$ & $\begin{array}{c}\text { Hemicellulose } \\
(\%)\end{array}$ & $\begin{array}{l}\text { Lignin } \\
\qquad \%)\end{array}$ \\
\hline Sugar cane bagasse & $32-48$ & $19-24$ & $23-32$ \\
\hline Sugar cane straw & $40-44$ & $30-32$ & $22-25$ \\
\hline Slsal (Agave Sisalana) & 73.1 & 14,2 & 11 \\
\hline
\end{tabular}

Source: adapted from Leão 2014

In recent years, Brazil has shown itself in the agricultural scenario as one of the largest exporters of manufactured natural fibers and sisal, as the main applications of 
industrialized sisal fiber in the automobile industry and also in the manufacture of ropes, twine, marine cables, carpets, bags, brooms, upholstery, crafts; in addition, industrial use in the manufacture of cellulosic masses for the production of highstrength Kraft paper, and other types of thin paper, such as cigarettes, filters, sanitary napkins, diapers, etc [2]

According to IEA (international energy agency) the biorefinery concept consists in valorising a wide variety of biomass forestry,agriculture, and aquaculture as well as many residues -into a broad range of products and energy. At the moment, different biorefinery concepts are under development, showing different stages of development (technology maturity).

\section{METHODOLOGY (ARIAL 12)}

The Methodology consisted of a bibliographic review and research on agave sisalana, production economics, utilization, state of the art of agave biorefinery and Brazilian Agave Sisalana production scenario.

For the biorefinery proposal the complexity of its installation was measured using the Biorefinery Complexity Index $(\mathrm{BCl})$. The Classification System is defined by four basic resources: Platform, Raw Material, Products and Processes. The $\mathrm{FCl}$ (Feature Complexity Index) assesses the technical and economic status of the technologies.

The criteria adopted for structuring the agave sisalana biorefinery model was the use of biomass without diversification of products, the focus was the production of Ethanol. The applicable values were identified using the TRL tables [2]. With this information it was possible to obtain the variables $\mathrm{FCl}$ and FC.

Besides $\mathrm{BCl}$, the biorefinery complexity profile (Biorefinery Complexity Profile - $\mathrm{BCP}$ ) was calculated, $\mathrm{BCP}$ is a number composed of the $\mathrm{BCl}$ and $\mathrm{FCl}$ of a biorefinery. both $\mathrm{BCP}$ and $\mathrm{BCl}$ were calculated as seen in the equations (1) and (2) respectively.

$$
\begin{gathered}
B C I=\sum_{i=1}^{4} \sum_{j=1}^{m} N F_{i, j} \cdot F C_{i, j} \\
B C P=B C I\left(F C I_{\text {Plataformas }} / F C I_{\text {Matérias-Primas }} / F C I_{\text {Produtos }} / F C I_{\text {processos }}\right)(2)
\end{gathered}
$$

From this review, and $\mathrm{BCP}$ and $\mathrm{BCI}$ measurement, was possible to notice the possibility of the use of the leaves residue also known as bagasse and the juice that is generated in the agave sisalana beneficiation for the production of ethanol $2 \mathrm{G}$ and other products due to its high fermentative capacity and the presence of many substances applicable in many industrial sectors.

\section{RESULTS AND DISCUSSION}

Characterization studies of the substances present in the Agave sisalana biomass demonstrate that the solid and liquid residues have potential not only for the ethanol $2 \mathrm{G}$ production but also as an organic fertilizer supplement, feeding ruminants, raw material for the production of corticosteroids, obtaining extracts with important biological activities, such as larvicidal, antimicrobial, ovicidal and antiparasitic.[3, 4,5]

Agave's liquid residue has been studied mainly for its pharmaceutical potential. The fermentation of Hecogenin found in Agave shows potential by producing substances 
that can be separated with the appropriate extraction processes, such as mannitol, which is a diuretic substance; kaempferol, which is a flavonoid of interest in the food industry; and steroidal saponins, which are the active ingredient in the synthesis of hormonal steroids the fluxogram for a proposal of a biorefinery is shown in Figure 1. [3]

Figure 1. Agave sisalana Leave Biorefinery Proposal

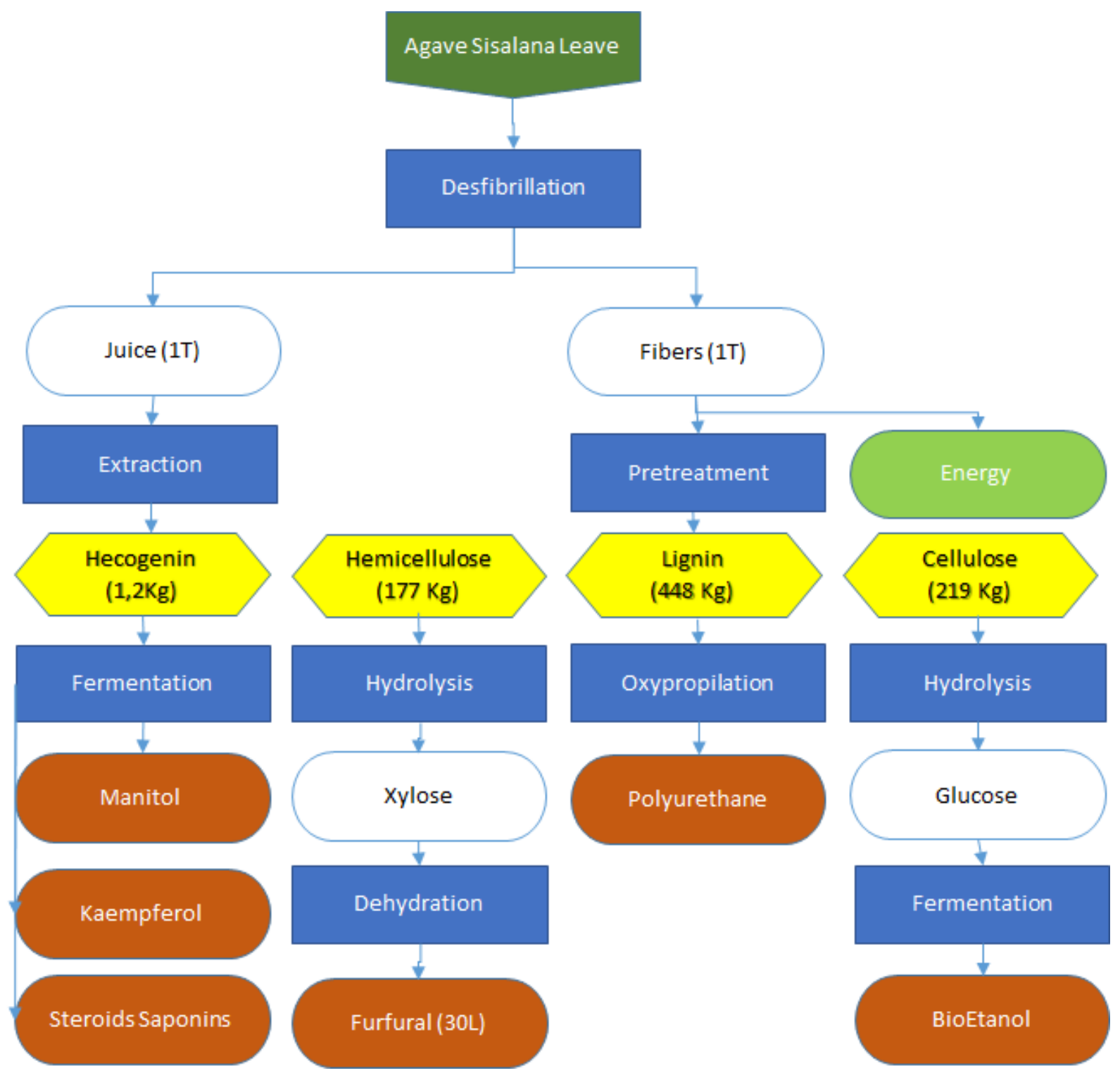

Source: Authors

Several studies have been done on the substances present in the juice, however each study uses a different method to obtain different substances. Inulins and Saponins are quite prominent among them, focused on the Agave genre. Inulin stands out for being a substance that also has bioenergetic potential for the production of bioethanol. $[3,6$, $7,8]$

With that shown, talking about the sisal bagasse which is a solid residue obtained with the agave beneficiation, this biomass contains high amounts of cellulose (20 to $40 \%$ of mass fraction on a dry basis), hemicellulose (25 to $40 \%$ ) and lignin (22 to $30 \%$ ). In 
this way, the bagasse also has energy potential in the production of ethanol and liquor from enzymatic hydrolysis. [3]

Talking about the Lignocellulosic fibers extracted from sisal, those materials are used to reinforce ligno polyurethanes forming composites. Lignin is the second most abundant biopolymer on Earth, behind only cellulose. It is noteworthy that the term biocomposite can be applied to materials in which one or more phases have a biological origin from renewable sources [9].

Due to the excellent mechanical properties, sisal fibers can be considered as good reinforcements for polymeric matrices. Generally, the use of vegetable fibers as a reinforcement for composite materials is justified by valuing a local resource under development and producing materials and technologies with reduced environmental impact

Among the chemical modifications already carried out on lignins, the oxypropylation reaction is the best known. A viable and promising approach to overcome the technical limitations and restrictions imposed by the polymeric nature of lignin when used directly as a macromonomer [10]. An advantage of the fiber / matrix impregnation process, is that PU reactions, depending on the reagents considered, can start at temperatures close to room temperature. With the hemicellulose present in agave sisalana There is an acidic hydrolysis that the pentoses in solution, after being separated from cellulose, lignin and ashes, are subjected to dehydration also in an acidic medium, which turns them into furfural as the main product

For each ton of bagasse, $100 \mathrm{~kg}$ of furfuraldehyde $(90 \mathrm{I})$ are obtained. Furfural is of great importance, mainly for the replacement of diesel oil, as well as raw material for chemical purposes. The process, in fact, enables the industrial production of furfural at a much lower price than that practiced in the national and international market. The price of furfuraldehyde production in this process allows it to re-enter the chemical industry as a raw material for extensive use, competing with products currently obtained from petrochemicals. In addition, it has a wide range of applications as pharmaceutical ingredients, for example, furazolidone, nitrofurazone and nitrofurantoin. It also has part of the production used for the synthesis of polymers (glass fibers, aviation resin and brakes), furan and Tetrahydrofuran (THF).

The production of 2 nd generation bioethanol or ethanol (E2G) by A. sisalana has several advantages such as its wide availability, low investment in technology, as it is resistant to long periods of drought and is easy to plant. Ethanol production from lignocellulosic materials such as Sisal, consists of the stages of pre-treatment, hydrolysis, fermentation and distillation. The first is an alternative to improve cellulose digestibility, since partial solubilization and / or degradation of hemicellulose and lignin occurs. In hydrolysis, whether enzymatic, acidic or alkaline, the main goal is to provide the fermentable sugars that are produced from cellulose and hemicellulose present in the form of Glucose and Xylose respectively.

Fermentation and distillation follow the same characteristics as the traditional production process, except for the fermentation of the fraction of C5 sugars present in the xylanolytic fraction, which is not passive to be fermented by the yeast Saccharomyces cerevisiae.[11]

With that shown, from all the opportunities seen for the use of agave processing residues, $\mathrm{BCP}, \mathrm{FCl}$ and $\mathrm{BCl}$ were calculated for the agave biorefinery proposal as it is shown in the Figure 2. 
Figure 2. Value of $\mathrm{BCl}$ and $\mathrm{BCP}$ for the case of A. Sisalana Biorefinery

\begin{tabular}{|c|c|c|c|c|}
\hline Features & Descrição & TRL & FC & $\mathrm{FCI}$ \\
\hline & & & & \\
\hline \multirow{4}{*}{ Platforms } & Hexose & 9 & 1 & \multirow{4}{*}{10} \\
\hline & Pentose & 7 & 3 & \\
\hline & Lignin & 7 & 3 & \\
\hline & Juice & 7 & 3 & \\
\hline Feedstock & Agave sisalana Leave & 8 & 2 & 2 \\
\hline & & & & \\
\hline \multirow{6}{*}{ Products } & Manitol & 5 & 5 & \multirow{6}{*}{20} \\
\hline & Kaempferol & 5 & 5 & \\
\hline & Steroids Saponins & 5 & 5 & \\
\hline & Furfural & 7 & 3 & \\
\hline & Polyurethane & 9 & 1 & \\
\hline & Ethanol & 9 & 1 & \\
\hline \multirow{11}{*}{ Process } & Defibrillation & 9 & 1 & \multirow{9}{*}{19} \\
\hline & Juice Extraction & 9 & 1 & \\
\hline & Fiber pretreatment & 7 & 3 & \\
\hline & Lignin Oxypropilation & 6 & 4 & \\
\hline & Fiber Combustion & 9 & 1 & \\
\hline & Xylose Enzymatic Hydrolisys & 7 & 3 & \\
\hline & Cellulose Enzymatic Hydrolisis & 8 & 2 & \\
\hline & Fermentation (C6) & 9 & 1 & \\
\hline & Dehydration & 7 & 3 & \\
\hline & BCI Total & & & 51 \\
\hline & \multicolumn{3}{|l|}{$B C P=28(7 / 2 / 4 / 15)$} & \\
\hline
\end{tabular}

Source: Authors

As expected, the biorefinery has a high degree of complexity among those focused on the use of biomass, according to the proposed methodology [2]. An example of how it reached this value is the carbon dioxide emitted in the fermentation which, despite not being counted as a product [2].

Lastly,the major contribution feature was "processes", which provides a dimension of the difficulty of a biorefinery with integrated processes. However, in a configuration where a biorefinery was structured as an industrial complex, each sector would be responsible for smaller parts of the processing. This breakdown of processes would reduce complexity. Finally, the complexity profile can also be represented in relation to each resource as can be seen in Figure 3. 
Figure 3.Biorefinery Complexity by resource

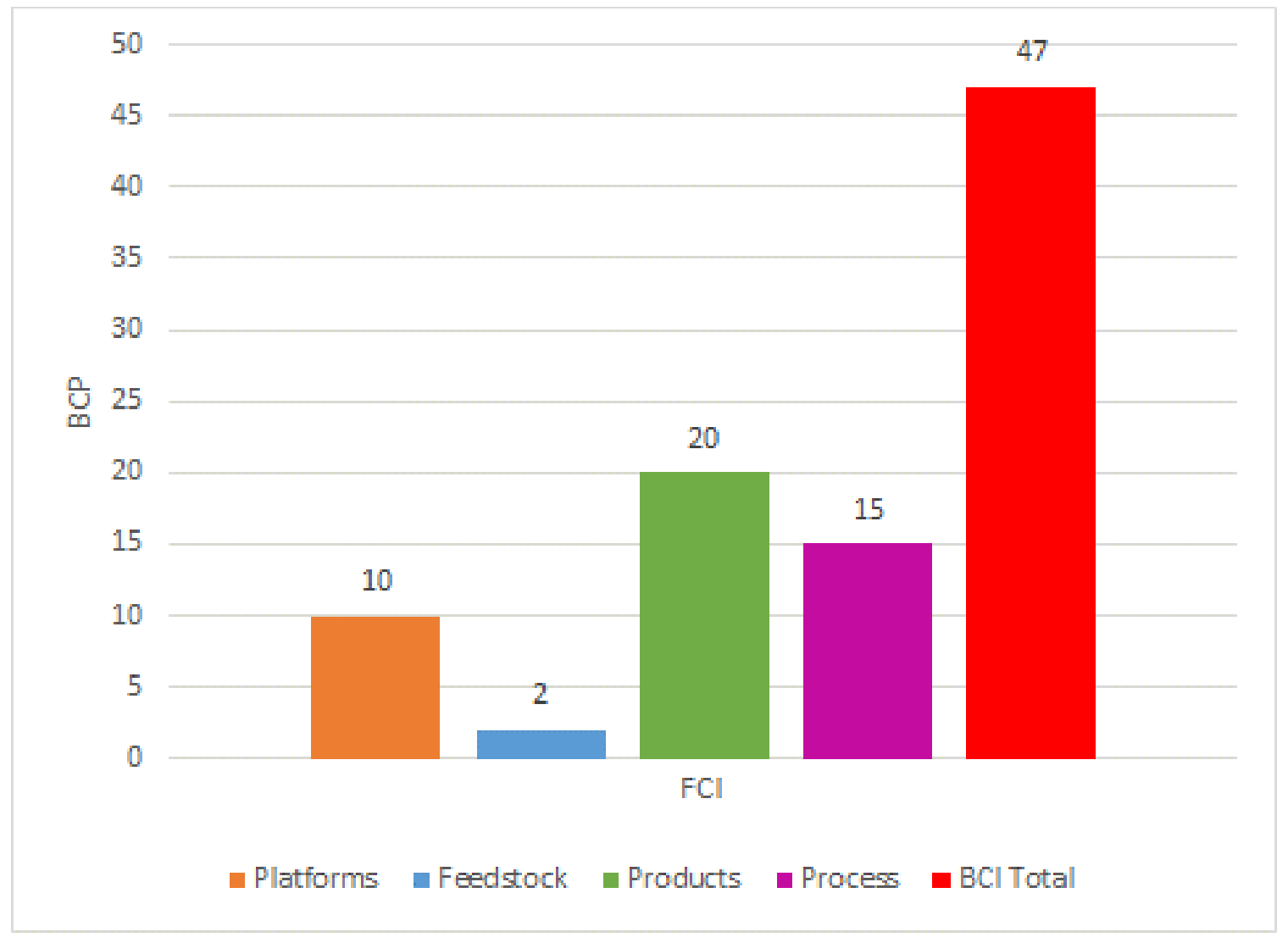

Source: Authors

\section{CONCLUSION}

Due to its low water requirements, high productivity in semi-arid lands, adaptability to high temperatures, resistance to drought and proven high yield of sugar I product conversion, Agave has gained recognition as a potential energy source that could be used in a biorefinery scheme as a raw material and comparable to traditional bioenergy raw materials.

Finally, additional studies, such as the life cycle and sustainability assessment of a biorefinery of different Agave species and regions, are needed to examine the environmental impact and cost efficiency of a functional plant in which the production of different products added value could potentially improve the Brazilian economy and industrial sector.

\section{REFERENCES}

${ }^{1}$ PÉREZ-PIMIENTA, J. A. Review: Recent developments in Agave performance as a drought-tolerant biofuel feedstock: agronomics, characterization, and biorefining Society of Chemical Industry and John Wiley \& Sons, Ltd Biofuels, Bioproducts and Biorefinary, v. 7, n. 4, p. 732-738, 2017.

2JUNGMEIER, G.; REE, R. VAN; JØRGENSEN, H.; et al. The Biorefinery Complexity Index. Austria, 2014. 
${ }^{3}$ SANTOS, J. D. G. et al. Chemicals from Agave sisalana Biomass: Isolation and Identification. International Journal of Molecular Science, v. 16, p. 8761-8771, 2015.

4 IBGE. Produção Agrícola - Lavoura Permanente, 2018. Disponível em: $<$ https://cidades.ibge.gov.br/brasil/pesquisa/15/12040>. Acesso em 22 de Junho de 2020.

${ }^{5}$ BEZERRA, G. S. Avaliação da produção simultânea de xilitol e etanol a partir do bagaço de sisal. Tese de Mestrado em Química, UFPB - João Pessoa, 2016.

${ }^{6}$ CUSHMAN, J. C. et al. Review: Development and use of bioenergy feedstocks for semi-arid and arid lands. Journal of Experimental Botany, Vol. 66, No. 14, p. 4177-4193, 2015

${ }^{7}$ DAVIS, S. C.; DOHLEMAN, F. G.; LONG, S. P. Review:The global potential for Agave as a biofuel feedstock. Journal Global Change Biology: Bioenergy, v. 3, p 6878,2011

${ }^{8}$ NAVA-CRUZ, N. Y. et al. Agave biotechnology: an overview. Critical Reviez Biotechnology, v. 35, n. 4, p. 546-559, 2015.

${ }^{9}$ FOWLER, P. A.; HUGHES, J. M.; ELIAS, R. M. Biocomposites: Technology, environmental credentials and market forces.Journal of the Science of Food and Agriculture, v. 86, n. 12, p. 1781-1789, 2006.

${ }^{10}$ LORA, J. H.; GLASSER, W. G. Recent industrial applications of lignin: A sustainable alternative to nonrenewable materials. Journal of Polymers and the Environment, v. 10, n. 1-2, p. 39-48, 2002.

${ }^{11}$ Cardoso, J. F., Silva, K. A., Godoy, P. H. M., Seolatto, A. A., Produção de Etanol a partir do Bagaço da Laranja. X Congresso Brasileiro de Engenharia Química Iniciação Científica. Universidade Federal do Rio de Janeiro, vol 1, 2014. 